\title{
Eighteenth and nineteenth century dental restoration, treatment and consequences in a British nobleman
}

\author{
M. Cox, ' J. Chandler, ${ }^{2}$ A. Boyle, ${ }^{3}$ P. Kneller, ${ }^{4}$ and R. Haslam, ${ }^{5}$
}

This paper examines unusual eighteenth and nineteenth century dental treatment and its consequences, in a nobleman excavated from beneath St. Nicholas' Church, Sevenoaks, Kent, UK in the early 1990s. This rare archaeological case exhibits erosion of dental enamel on the labial surface of all the anterior dentition. A programme of historical research suggests that this might be attributed to the application of an acid-based dental tincture or the use of an abrasive substance to whiten the teeth. Palliative treatment for the consequence of this application was prescribed by Dr Robert Blake of Dublin. Further, it bears witness to three dental restorations, two of gold and one tin. The two gold (foil) fillings are an occlusal in the upper-right second molar and a cervical on the labial surface of the upper left canine. The tin filling is an occlusal in the upper left second molar. Excavation of the carious tissue appears to have been undertaken using a spoon shaped implement.

A rchaeological excavation beneath $\mathrm{St}$. Nicholas Church, Sevenoaks, Kent, England recovered around 450 burials, 84 of which were post medieval and recovered from lead coffins with legible breast-plates stating their name, age and date of death. ${ }^{1}$ The remains were subject to a reburial order and consequently, only briefly available for examination. This paper concerns the oral health, dental restorations and treatment evident in the remains of Charles Whitworth, who had been buried in an elaborately decorated triple-shelled lead coffin ${ }^{2}$ with a well-preserved brass

\footnotetext{
${ }^{1}$ Professor of Forensic Archaeology and Anthropology, ${ }^{4}$ Senior Lecturer in Environmental Sciences, ${ }^{5}$ Director of Investigative Support Unit, School of Conservation Sciences, Bournemouth University, Talbot Campus, Poole, Dorset BH12 5BB; ${ }^{2}$ Historian, Salisbury and South Wiltshire Museum, The King's House, 65 The Close, Salisbury, Wiltshire SP1 2EN;

${ }^{3}$ Osteoarchaeologist, Oxford Archaeological Unit, Janus House, Osney Mead, Oxford OX2 OES

${ }^{*}$ Correspondence to: Professor Margaret Cox, School of Conservation Sciences, Bournemouth University,

Talbot Campus, Poole BH12 5BB

email:mcox@bournemouth.ac.uk

Refereed Paper

Received 20.05.99; Accepted 12.04.00

(c) British Dental Journal 2000; 189: 593-596
}

breast-plate. This was inscribed: 'The Right Honourable Charles Earl Whitworth, Viscount Whitworth of Adgbaston, Baron Adgbaston in the County of Stafford, Lord Whitworth of Newport Pratt in the County of Galway in the peerage of Ireland, Knight Grand Cross of the Bath and a Privy Counsellor, Died 13 May $1825^{\prime}$ (sic). He died aged 71 years.

Whitworth's dentition provided a brief opportunity to examine restoration techniques that must have been in use before

In brief

- An unusual example of late eighteenth/early nineteenth century dentistry in a nobleman excavated from beneath a church in Kent.

- The first ever reported case of enamel erosion of the labial surface of anterior dentition in the UK.

- Discussion and description of the possible effects on dental enamel of the use of dental tinctures.

- Scientific analysis of dental restorations from this period his death in 1825 . It was notable because he had three dental restorations in his upper dentition. Gold fillings in the upper-left canine and right second molar, and a black material in the upper-left second molar. Post-medieval dental restorations are rare in the archaeological literature ${ }^{3,4}$ reflecting the expensive nature of such treatment, its consequent exclusivity, and the small number of controlled exhumations and archaeological excavations of this period. Further to this, Whitworth's anterior upper and lower dentition exhibited an extremely rare loss of labial dental enamel. This was associated with the cemento-enamel junction, resembling arrested caries (Fig. 1) and is the first instance of this condition to be reported in British archaeological material.

Enamel erosion is the dissolution of the surface enamel (apatite) by a physicochemical process involving acids. ${ }^{5}$ While there is a published literature on erosion of the lingual surface of dentition, there has been less recent interest in labial erosion. The literature on enamel erosion and abrasion considers its relationship to such factors as dietary, regurgitative and industrial erosion, ${ }^{6}$ consumption of acidic foods and drinks and modern dental hygiene. $^{7-9}$

In an eighteenth and nineteenth century context, the loss of labial enamel on anterior teeth, particularly along the cemento-enamel junction, is likely to reflect the use of an abrasive tooth powder or an acidic and erosive dental tincture. Such treatments were advocated to: '...eradicate the scurvy and tartar from the gums; make the teeth, however yellow, beautifully white; fasten such as are loose...' (Advertising for Hudson's botanic tooth-powder and tincture). ${ }^{10}$

\section{Charles Whitworth (I752-I 825)}

Whitworth had a varied military and diplomatic career. Of relevance here, he was Lord Lieutenant of Ireland from 1813-1817. Thereafter spending most of his time at Knole, near Sevenoaks, Kent, dying there on 13 May $1825 .{ }^{11-13}$ Whitworth and his wife, 


\section{GENERAL dental history}

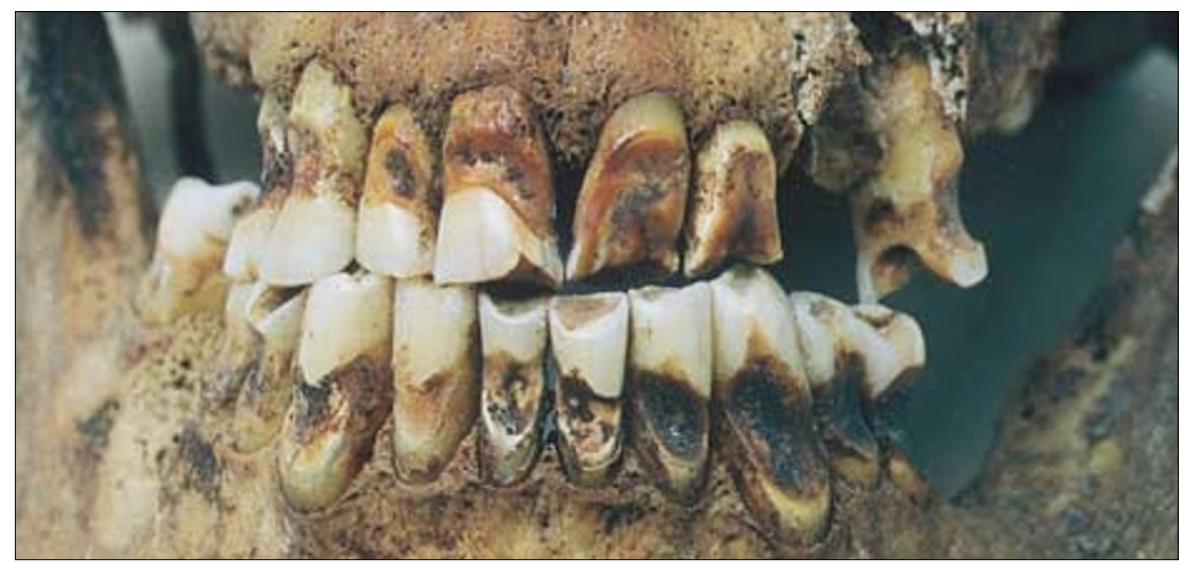

Fig. I Whitworth's anterior dentition showing the destruction of dental enamel on the labial surface and its contiguous extent. This was taken after the removal of teeth with gold restorations for analysis

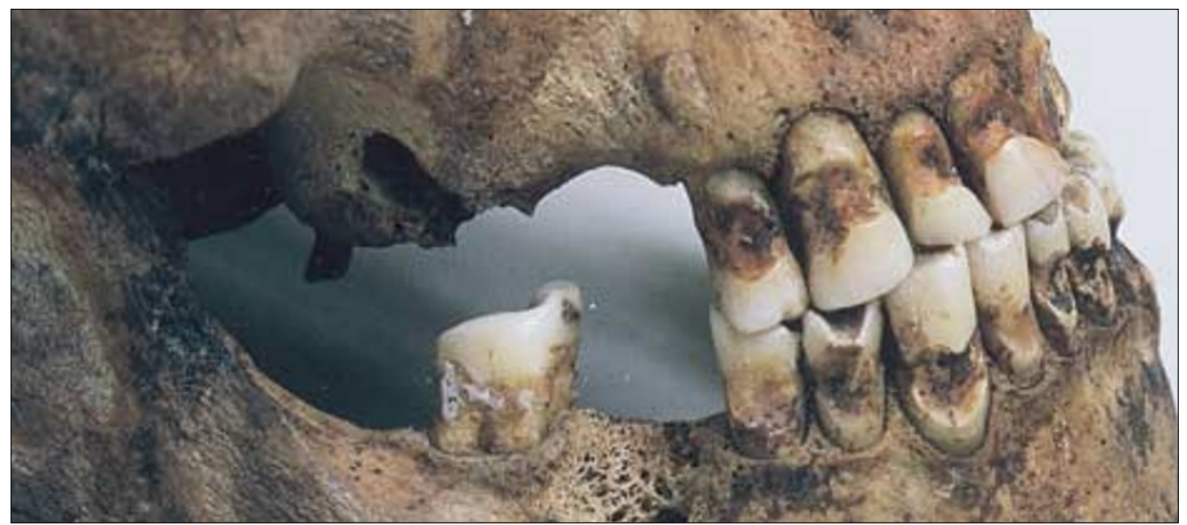

Fig. 2 The right labial anterior dentition, showing and nature of the erosion of dental enamel and bone remodelling following ante-mortem tooth loss. This was also taken after the removal of teeth with gold restorations for analysis

the widowed Duchess of Dorset, were extremely wealthy aristocrats, and prodigious spenders. They were supplied by the highest quality establishments in London, Paris, Dublin and elsewhere. Their scrupulous keeping of accounts and records ${ }^{12}$ of both a personal and financial nature, particularly in relation to apothecaries, druggists and dentists proved to be relevant to this research. ${ }^{14}$

\section{Whitworth's dental health}

A range of macroscopic and microscopic analysis was undertaken examining Whitworth's dental and oral health and restorations. He had clearly experienced considerable dental disease during his lifetime. This is reflected not only in the presence of dental restorations, but also in the antemortem loss of all lower left molars and the first right molar, the crypt of which was still remodelling (Fig. 2). The upper left first molar and right second premolar, and right first and third molars were also lost ante-mortem, though a fragment of the root remained from the right first molar. Extant caries were evident on the upper left first premolar with the entire crown of the adjacent canine having been destroyed. Apical abscesses (buccal) were associated with the upper right second molar (tooth with the tin filling) and the lower right first molar. Whitworth had an edge to edge bite and consequently, marked attrition to the incisal edge of his central and lateral incisors. His upper left third molar had not erupted.

The restorations - removal of carious tissue

The gold restoration in the upper-right second molar was deliberately and easily dislodged during examination to provide an opportunity to examine the excavated surface of the cavity, using scanning electron microscopy (SEM), in order to assess the method of excavation, and to examine the filling itself in more detail (Fig. 3). There were roughly parallel U-shaped marks running around the tooth cavity (Fig. 4), denoting excavation using a blunt edged instrument, with irregular vertical cracks running down into the cavity. It is impossible to assess if the former were caused by the use of such drills as were available at that time. The latter may reflect drying out cracks in the dentine.

The restorations - filling materials The filling materials used in the occlusal surface of this tooth and the anterior enamel/cementum junction of the upper left canine, were examined using an energy dispersive $\mathrm{x}$-ray detector (EDX) fitted to the SEM. This proved to be high carat gold foil that appears to have been condensed and pushed into the cavity. In the case of the molar, the gold foil appears to have been applied in a single application (Fig. 3). Crushing and deformation of the material on the occlusal surface had occurred, as would be expected with such a soft material. Two applications of foil appear to have been used for the canine (examined after being sectioned and polished - the teeth were extracted from the maxilla and set in a poly-

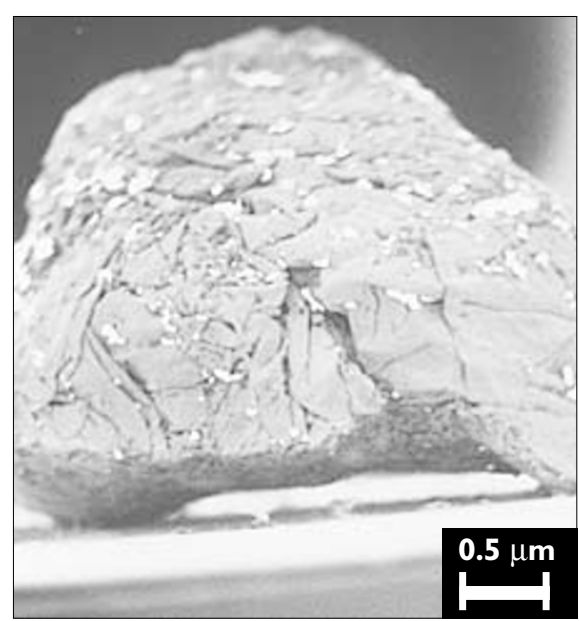

Fig. 3 SEM micrograph showing the gold filling removed from the upper right molar depicting the folds of the foil and the compressed occlusal surface

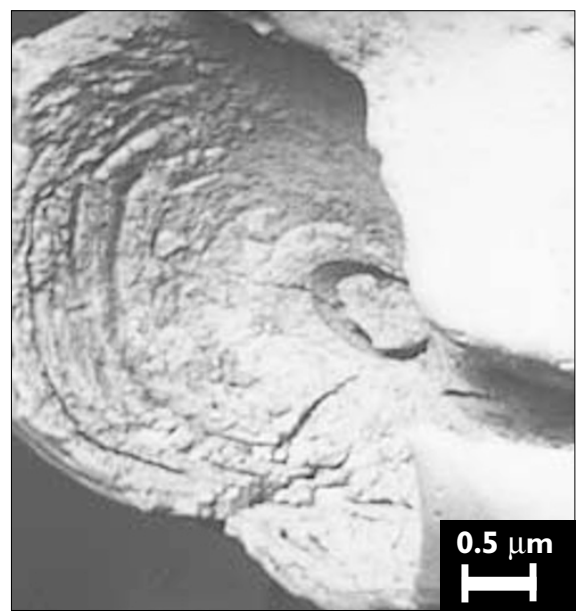

Fig. 4 SEM micrograph of the upper right second molar following the removal of the gold filling. Note the circular lesions created by the excavation of carious material probably using a blunt edged instrument 
Table I

Elements other than tin in the dental restoration in the upper left second molar

Additional elements in the tin filling using AAS

Cadmium

$$
\approx 0.2 \mathrm{mg} / \mathrm{g}
$$

Lead

$\approx 0.2 \mathrm{mg} / \mathrm{g}$

Strontium

$\approx 0.6 \mathrm{mg} / \mathrm{g}$ mer cast before sectioning longitudinally with a diamond saw; micrographs were taken using an Hitachi S-450 scanning electron microscope) (Figs 5a and b). The first was much less firmly compressed than the latter. This filling does not appear to be well adapted although there is no evidence that carious decay continued after the restoration. Gold had been in use as a filling material since at least 1516, though only rarely, and was evident in two individuals at Christ Church, Spitalfields both of whom were interred prior to 1809.3

The third filling, in the occlusal surface of the upper left second molar, was analysed initially by EDX. This showed the filling to be largely of tin with a trace of antimony, a commonly found impurity in tin (A small amount of filling was removed using a tungsten carbide tipped dental rasp. This was weighed and treated overnight with a 1:2 mixture of hydrochloric (36\%) and nitric (70\%) acids. The solution was then made up to a standard volume with distilled water and the solution reserved for analysis by AAS. The analysis was performed using a ATIUnicam atomic absorption spectrophotometer using an air/acetylene fuel mixture with a $100 \mathrm{~mm}$ burner). Little is published about the use of tin as a filling material. Further analysis was undertaken using atomic absorption spectrometry (AAS) with standard techniques for cadmium, lead and antimony. These showed that the filling material was tin with no deliberately added elements (see Table 1). Fourier transform infrared spectroscopy did not detect any organic residue from a glue or other adhesive matrix.

Unfortunately, historical research has shed no light on the timing and provenance of Whitworth's dental restorations. The only records that survive for his dental care relate to bills from a Dublin tradesman, Alfred de Lessart ${ }^{15}$ and date to 1823-24. Since Whitworth was in Dublin between 1813 and 1817, it may be reason- able to suppose that he first sought relief and/or treatment there during this period and continued to follow advice and treatment given at that time.

\section{Destruction of the labial enamel of the anterior dentition}

The destruction of buccolabial enamel on the surviving anterior dentition is shown in Figure 1 . This was particularly focussed on the cementum/enamel junction in most cases and was most severe on the upper left incisors where the anterior enamel was totally destroyed. While this initially appeared to be arrested caries, the contiguous nature (Fig. 2) and extent of the loss cast doubt on this diagnosis as did the hard nature of the surface of the teeth. ${ }^{9}$ Furthermore, when clean, the affected areas displayed the typical clear edged, disc-shaped, yellowish cavities described in Stone which are commonly associated with erosion. ${ }^{9}$ Subsequent examination, when combined with a programme of targetted historical research, suggested that the enamel may have been eroded by a destructive agent. That the pathology is greater on the left side,

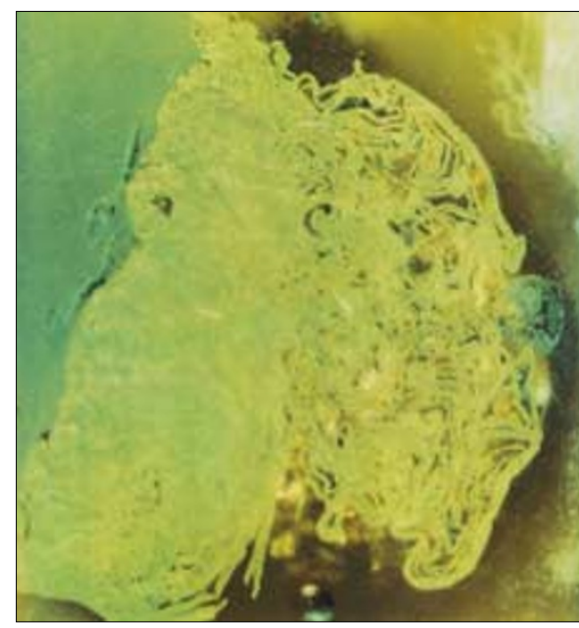

Fig. 5 (a) A section of the upper left canine, showing the filling at the cemento-enamel junction. Taken using a low powered microscope at $\times 10$ magnification, it shows that the gold foil filling was applied in two stages and that the first layer was not as compacted as the second. (b) SEM micrograph showing detail of the root filling and the different levels of compaction of the gold foil

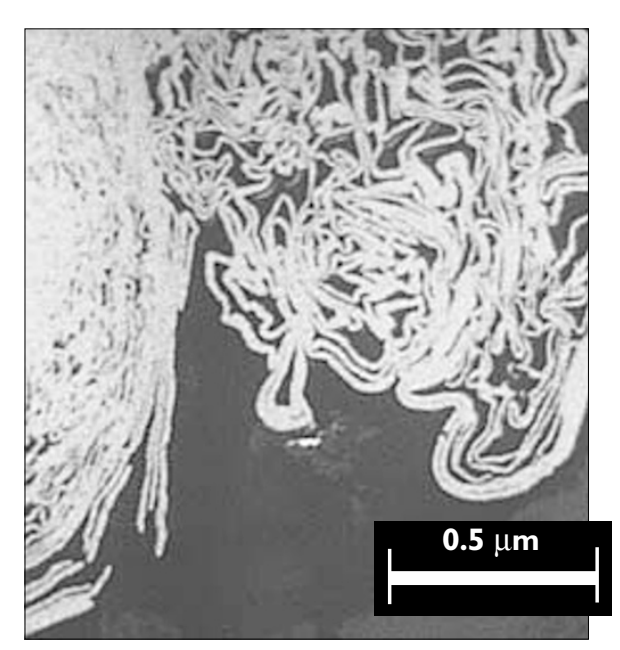

particularly of the upper dentition, could suggest that a right-handed man was applying an abrasive or erosive substances on a tooth brush, or similar, and rubbing his teeth. ${ }^{9}$ The nature of that agent, was investigated by recourse to contemporary commentary and treatises.

Historical research revealed that Whitworth was consulting a dentist, Alfred De Lessart, of No. 7 William Street, Dublin during his latter years. ${ }^{15}$ His purchases from Lessart included 'Dr Blake's tooth-powder' and 'Dr Blake's tincture'.

\section{Tooth powders and dental tinctures}

Patented tinctures and powders proliferated in the eighteenth and nineteenth centuries particularly in response to periodontal disease and the removal of calculus. Most early potions comprise abrasive pastes including such substances as shell, coral and ground pebbles. ${ }^{10}$ Others could be harmless ${ }^{16,17}$ while some could be highly acidic often based on tartaric acid. ${ }^{16}$ However, while cleaning teeth and gums with tinctures with an acid or abrasive base would have removed calculus, it would also have etched and abraded the dental enamel. ${ }^{16}$ Despite the consequences of using dental tinctures being known and clinically demonstrated as early as $1768,{ }^{16}$ Figures 1 and 2 suggest that Whitworth 
might well have resorted to the use of such a substance to redress an oral health problem. A contemporary pharmacopoeia lists 12 tooth powders, most of which contained cream of tartar and only two of which were relatively harmless. ${ }^{18}$ The siting of Whitworth's lower enamel loss in particular, would suggest that he was aiming to remove or resolve a condition along the enamel/cementum junction, possibly calculus (though there is no evidence of calculus on his posterior teeth), or halt receding gums. Calculus is not uncommonly seen in this position in archaeological material. Alternatively, brushing teeth in a horizontal direction may produce wear at the cervical margin. ${ }^{9}$ With his upper dentition it is likely that he was also concerned to whiten his teeth as the erosion is more widespread. If this was so, was Dr Blake's tincture or powder responsible?

\section{Dr Blake and his tincture}

Dr Blake was almost certainly Robert Blake MD, who by 1803 was Dublin's leading dentist, practising from 19 William Street (a few doors away from Lessart's premises). He had developed a large practice by 1821 when he was appointed as the first Irish state dentist. ${ }^{19,20} \mathrm{He}$ died in 1822 . It would appear, therefore, that Blake was one of Dublin's foremost dentists during Whitworth's sojourn there as lord lieutenant in 1813-17. As such it would have been entirely appropriate for Blake to have ministered to Whitworth. Perhaps the appearance of Dr Blake's tincture in Whitworth's records in the years 1823-24 is explained by Blake's death the previous year, and a new supplier (Lessart) taking over his business.

The formulas for Dr Blake's tincture and powder are not, unfortunately, included in any contemporary pharmacopoeia. ${ }^{18}$ In his published work, ${ }^{21}$ Blake was very critical of tooth powders, essences and lotions in widespread usage, because he recognised and had proved by experiment their corrosive effect. Consequently, it seems unlikely that his products were responsible for the destruction of Whitworth's dental enamel. Dental practitioners of his own and subsequent generations praised Blake's work, ${ }^{20}$ and his enlightened views have been recog- nised by modern historians of dentistry. ${ }^{22}$ It is possible, that the tincture and powder which bore his name may well have been taken by Whitworth as palliatives to mollify the painful effects of earlier damage caused possibly by tartaric acid in tooth-cleaning preparations or abrasive powders or pastes.

\section{Conclusion}

This study examining dental restorations confirms some of the techniques and developments described in the historical literature and provides useful additional detail relating to their practice and effectiveness. Examination of the loss of enamel on the labial surface of Whitworth's anterior dentition suggests that efforts to whiten his teeth, and possibly remove calculus, proved to be extremely damaging to his oral health.

Given that most post-medieval excavations of cemetery assemblages are those of the middle or upper socio-economic classes, it seems improbable that this is the only example in British museum collections. Recording conditions such as erosion or abrasion are not standard procedures in UK anthropology, consequently, other cases may exist unrecorded. It is considered that awareness of this condition would be increased by its inclusion in standard anthropological recording systems.

Thanks are due to the Parochial Church Council, St Nicholas' Church, Sevenoaks and the Oxford Archaeological Unit for providing the brief opportunity to examine this unusual and important 19th century skull. The School of Conservation Sciences, Bournemouth University provided financial support. Angela Boyle provided background information to the excavations at St Nicholas' Church, Sevenoaks, Dr John Chandler undertook historical research into Whitworth's life and dental history and Paul Kneller and Rob Haslam undertook the scientific analysis of the dental restorations. Staff at the Centre for Kentish Studies, Maidstone and the Wellcome Institute Library, London are thanked for their assistance as are the anonymous referees and Tony Rhodes and Julian Mitchell for their helpful comments.

1 Boyle A, Keevill G. To the praise of the dead and anatomie: The analysis of post-medieval burials at St Nicholas, Sevenoaks, Kent. In M. Cox M. (ed). Grave concerns: death and burial in post-medieval England 1700-1850. pp85-99. York: Council for British Archaeology, 1998.

2 Reeve J, Adams M. The Spitalfields Project Volume 1-The Archaeology: Across the Styx. York: Council for British Archaeology, 1993.
3 Whittaker D. Oral Health. In Molleson T, Cox M (eds). The Spitalfields Project Vol 2 - the Anthropology: The Middling Sort. pp 49-63. York: Council for British Archaeology. 1993.

4 Glenner R A, Willey P, Sledzik P S, Junger E P. Dental fillings from Civil War skulls: what do they tell us? J Am Dent Ass 1996; 127: 16711677.

5 Ferguson D B. Oral Bioscience. Edinburgh: Churchill Livingstone, 1999.

6 Smith B G N, Knight J K A. Comparison of patterns of tooth wear with aetiological factors. Br Dent J 1984; 157: 16-19.

7 Robb N, Cruwys E, Smith B G N. Regurgitative erosion as a possible cause of tooth wear in ancient British populations. Archs Oral Biol 1991; 36: 595-602.

8 Irish J P. First evidence of LSAMAT in non native Americans - historic Senegalese from West Africa. Am J Phys Anthrop 1997; 102: 141-146.

9 Farmer E D, Lawton F E. Stone's Oral and Dental Diseases. Edinburgh and London: E \& S Livingstone Ltd, 1966.

10 Bennion E. Antique Dental Instruments. London: Sotheby's, 1986.

11 Anon. Lord Charles Whitworth, Public characters of 1805. London: Publisher not stated, 1805.

12 Sackville-West V. Knole and the Sackvilles. London: Heineman, 1922.

13 Kent Archives Office. Maidstone. CPU U269 A252.

14 Their records survive in the Sackville Manuscripts (CKS U269) in the Centre for Kentish Studies (Kent Archives Office, Maidstone). Some official and private papers also exist in the Public Records Office, Kew. For the purposes of this paper, the most important accumulation at CKS is a series of vouchers, bills and receipts (CKS U269 A252) which date from 1798 to 1825 . Several thousands of such items have been examined.

15 CPU U269 A252/35 Bill to Whitworth from Lessart, Dublin 1824; A252/36 Bill from Lessart 1824.

16 Hillam C. Brass plate and brazen impudence: dental practice in the provinces, 1755-1855. Liverpool: Liverpool University Press, 1990.

17 Brown P S. Medicines advertised in 18th century Bath newspapers. Med Hist 1976; 20: 152-168.

18 Gray S F. A supplement to the pharmacopoeia; being a treatise on pharmacology in general. 3rd ed. London. Publisher not stated. 1824.

19 Cohen R A. A general history of dentistry from the 18th century, with special reference to Irish practitioners. Irish J Med Sci 6th Series. 1952; 315: 128-135.

20 Cameron, Sir Charles. History of the Royal College of Surgeons in Ireland and of the Irish School of Medicine. Dublin: Fannin and Co., 1886.

21 Blake R. An essay on the structure and formation of the teeth in man and various animals. Dublin: William Porter, 1981.

22 Held A J. Periodontology, from its origins up to 1980: a survey. Boston: Birkhauser, 1989. 